\title{
QUEEN'S
UNIVERSITY
BELFAST
}

\section{The problem with feedback}

Foster-Collins, H., Conn, R. L., Dornan, T., Lloyd, M., \& Mattick, K. (2021). The problem with feedback. MedEdPublish, 10(1). https://doi.org/10.15694/mep.2021.000128.1

\author{
Published in: \\ MedEdPublish
}

Document Version:

Publisher's PDF, also known as Version of record

Queen's University Belfast - Research Portal:

Link to publication record in Queen's University Belfast Research Portal

\section{Publisher rights}

Copyright 2021 the authors.

This is an open access article published under a Creative Commons Attribution- ShareAlike License

(https://creativecommons.org/licenses/by-sa/4.0/), which permits unrestricted use, distribution and reproduction in any medium, provided the author and source are cited, and new contributions are distributed under the same license.

\section{General rights}

Copyright for the publications made accessible via the Queen's University Belfast Research Portal is retained by the author(s) and / or other copyright owners and it is a condition of accessing these publications that users recognise and abide by the legal requirements associated with these rights.

\section{Take down policy}

The Research Portal is Queen's institutional repository that provides access to Queen's research output. Every effort has been made to ensure that content in the Research Portal does not infringe any person's rights, or applicable UK laws. If you discover content in the Research Portal that you believe breaches copyright or violates any law, please contact openaccess@qub.ac.uk. 


\title{
The problem with feedback
}

\section{Helen Foster-Collins[1], Richard Conn[2], Tim Dornan[2], Michael Lloyd[2], Karen Mattick[1]}

Corresponding author: Dr Helen Foster-Collins h.foster-collins2@exeter.ac.uk

Institution: 1. University of Exeter, 2. Queen's University Belfast

Categories: Educational Strategies, Educational Theory, Postgraduate (including Speciality Training), Research

in Health Professions Education

Received: $12 / 10 / 2020$

Published: 15/05/2021

\begin{abstract}
Feedback can be a powerful tool for promoting healthcare safety. However, 'feedback' as a concept tends to embody a number of implicit assumptions arising from behaviourist educational traditions, such as power differentials between feedback providers and receivers, unidirectionality of transmission, and simple notions of 'error'. Such assumptions can present challenges when designing and implementing feedback initiatives to address complex problems within healthcare such as improving prescribing. Sociocultural conceptions of feedback may be helpful in such cases, so that correspondingly complex solutions can be formulated.

The purpose of this article therefore, is to step back and reconsider the nature and value of the term 'feedback' when applied to complex healthcare problems. We consider a number of different conceptions, definitions and understandings of feedback, using our own research on optimising prescribing as a case study and drawing upon our joint reflexive discussions as a team. In doing so, we examine the differences between simple, complicated and complex problems and how these might relate to feedback in medical education. We also explore alternative but related terms to feedback, considering their similarities, differences, and the appropriateness of each when applied to complex activities such as prescribing. Finally, we reflect on the dilemma of whether the medical education community should persevere with using a term which eludes embedded shared conceptualisation, perhaps redefining it to better reflect contemporary usage, or embrace a different term altogether.
\end{abstract}

By sharing our experiences as a research team grappling with a challenging topic, we hope to engage with the wider community and their insights, in order to benefit our own research and the medical education research field.

Keywords: feedback; medical education; terminology; prescribing errors; optimising prescribing; improving prescribing; healthcare education interventions

\section{Introduction: why talk about feedback?}

At its simplest, feedback may be defined as any 'information provided by an agent (e.g., teacher, peer, book, parent, self, experience) regarding aspects of one's performance or understanding' (Hattie and Timperley, 2007). Such 
information is delivered with the aim of closing the 'gap' between 'appropriate standards' and performance (Boud and Molloy, 2013), or intended and actual outcomes (Sadler, 1989). However, 'feedback' is not always explicitly defined or discussed in literature which uses the term (Ridder et al., 2008), leaving it open to interpretation. Educators therefore inevitably draw upon their own understandings of what it is to give or receive feedback, influenced by previous educational experiences and by wider societal understandings, which themselves often have origins in behaviourist educational traditions.

Behaviourist theories of education generally conceptualise learning as a cognitive activity undertaken by individuals (Beckett and Hager, 2002). Knowledge is seen as relatively static, and transferable from one person to another. Conventionally, this involves a teacher (who is the expert), explaining topics verbally or in written form to a learner (who is the novice) and a more or less passive 'container' for new knowledge (Bereiter, 2002; Hager, 2004). The learner may subsequently reflect upon this knowledge and modify future plans based upon these new understandings. Such approaches may, to an extent, apply to specific types of learning such as the rote memorisation of facts or learning the steps of routine procedures. Feedback in these instances may be fairly straightforward, consisting of affirmation or correction; for example, the substitution of correct facts for incorrect ones (notwithstanding social factors such as how feedback is delivered and the effects of this on the receiver). However, the tasks which healthcare professionals undertake are frequently much more involved; requiring the synthesis of changing signs and symptoms with current medical knowledge (Hancock and Mattick, 2012), collaboration and interaction with other professionals, and decision-making which is embedded in wider social and organisational systems (Bull, Mattick and Postlethwaite, 2013).

Sociocultural theories of learning can be beneficial for understanding how learning operates in such contexts. In particular, highlighting the collaborative and social nature of learning in the workplace, of ten undertaken with and alongside others, which may involve modelling, observation and joint activity, questioning by both learners and educators, and the co-production of meaning through discussion. Learning within healthcare may also require an understanding of local social and organisational contexts. Feedback in these environments therefore needs to be more nuanced then simple correction of error, due to complexity of - the situations encountered, gaining a comprehensive understanding of the 'problems' to be resolved, and the solutions devised to address these. Prescribing is one such activity which is typically complex, and this brings us to the distinction between problems which are simple, complicated and complex.

\section{Simple, complicated and complex problems}

Problems, and the interventions used to address them, have been described as simple, complicated or complex (Rogers, 2008). Simple problems such as following a recipe might be solved by following a standardised set of instructions (i.e. the recipe) and, so long as these instructions are good ones and carefully followed, one can be confident of a good result (Glouberman and Zimmerman, 2004). More complicated problems, such as sending a rocket to the moon, require specific expertise and the solving of different sub-problems, but one can learn from the mistakes and successes of the past meaning that the outcomes of future endeavours are relatively predictable. Finally, there are problems which may be described as complex, due to factors which are uncertain and changeable over time, situated in local contexts, operating on multiple levels, and interacting in non-linear, unpredictable ways. Raising a child is one such type of challenge, in which neither expertise nor the strict application of rules and principles can overcome the inherent uncertainty of outcome. Rather, tailored solutions, modified as circumstances arise, are the norm.

In Table 1 are described the features of these different types of problem, using illustrative examples from prescribing. This process typically entails the solving of simple and complicated problems, such as filling out the 
allergy section of a prescription chart and calculating drug doses using a formula, but is also made complex through the influence of many interacting individual and systemic factors, which lead to varying, unpredictable outcomes. Due to this complexity, there are no single solutions or 'answers'; prescribing rests upon professional judgement, using the best knowledge available at the time, often drawing upon the perspectives and expertise of multiple professionals.

Table 1: The features of simple, complicated and complex problems ${ }^{[a]}$, using the example of prescribing enoxaparin.

\begin{tabular}{|c|c|c|}
\hline Problem type & Features & $\begin{array}{l}\text { Documentation of allergy section on prescription } \\
\text { chart: e.g. rash with enoxaparin }\end{array}$ \\
\hline \multirow{5}{*}{$\begin{array}{l}\text { Simple } \\
\text { Singular, stable, } \\
\text { solvable problems } \\
\text { linear, e.g. following } \\
\text { a recipe }\end{array}$} & $\begin{array}{l}\text { 1. Formal instructions or procedures } \\
\text { essential }\end{array}$ & $\begin{array}{l}\text { There is a standard procedure for completing the } \\
\text { allergy section on a prescription chart }\end{array}$ \\
\hline & $\begin{array}{l}\text { 2. Replication is straightforward and } \\
\text { allows testing }\end{array}$ & This procedure can be learned and repeated \\
\hline & $\begin{array}{l}\text { 3. Experience/expertise are helpful } \\
\text { (e.g. specific techniques or } \\
\text { terminology) but not essential }\end{array}$ & $\begin{array}{l}\text { With repetition, procedures may become routine and } \\
\text { details memorised (e.g. abbreviations such as NKDA } \\
\text { - No Known Drug Allergies), but one might also } \\
\text { consult external documents }\end{array}$ \\
\hline & 4. Standardisation of outcomes & $\begin{array}{l}\text { Given the same input (e.g. patient details on file and } \\
\text { medication prescribed), the output should be the same } \\
\text { i.e. the allergy chart should contain the same } \\
\text { information }\end{array}$ \\
\hline & $\begin{array}{l}\text { 5. The best instructions should give the } \\
\text { best results }\end{array}$ & $\begin{array}{l}\text { Prescribers can be given tips on how to ensure the } \\
\text { chart is completed correctly and legibly }\end{array}$ \\
\hline \multirow{6}{*}{$\begin{array}{l}\text { Complicated } \\
\text { Composed of } \\
\text { multiple interacting } \\
\text { elements and } \\
\text { subsets of problems, } \\
\text { e.g. sending a rocket } \\
\text { to the moon }\end{array}$} & & $\begin{array}{l}\text { Performing a drug calculation: e.g. 1mg/kg twice } \\
\text { daily dose of enoxaparin for an } 80 \mathrm{~kg} \text { patient }\end{array}$ \\
\hline & $\begin{array}{l}\text { 1. Formulae are necessary but not } \\
\text { sufficient }\end{array}$ & $\begin{array}{l}\text { Formulae are necessary, but other components are } \\
\text { also required e.g. observation of characteristics such } \\
\text { as body weight }\end{array}$ \\
\hline & $\begin{array}{l}\text { 2. Experience of procedures and } \\
\text { obtaining good results increases } \\
\text { assurance of future success }\end{array}$ & $\begin{array}{l}\text { With experience of doing calculations, they should } \\
\text { become more accurate }\end{array}$ \\
\hline & $\begin{array}{l}\text { 3. Specialised expertise required, may } \\
\text { require coordination of } \\
\text { components/teams }\end{array}$ & $\begin{array}{l}\text { For instance, the ability to perform mathematical } \\
\text { calculations such as converting between ratios and } \\
\text { percentages }\end{array}$ \\
\hline & $\begin{array}{l}\text { 4. The problem and outcomes desired } \\
\text { are similar on each occasion }\end{array}$ & $\begin{array}{l}\text { Although each calculation may be slightly different, } \\
\text { there a set number of skills which, once acquired, can } \\
\text { be used to solve future calculations }\end{array}$ \\
\hline & $\begin{array}{l}\text { 5. Outcomes are relatively predictable, } \\
\text { if known solutions to common issues } \\
\text { are used }\end{array}$ & $\begin{array}{l}\text { Given the same variables, there should be the same } \\
\text { result (i.e. there is a correct answer), problems may } \\
\text { arise from errors of measurement or mathematics }\end{array}$ \\
\hline
\end{tabular}




\begin{tabular}{|c|c|c|}
\hline \multirow{6}{*}{$\begin{array}{l}\text { Complex } \\
\text { Dynamic, situated, } \\
\text { multi-level, non- } \\
\text { linear, elements of } \\
\text { uncertainty and } \\
\text { ambiguity e.g. } \\
\text { raising a child }\end{array}$} & & $\begin{array}{l}\text { Prescribing: e.g. deciding on treatment for a } \\
\text { suspected pulmonary embolism. }\end{array}$ \\
\hline & 1. Formulae of limited value & $\begin{array}{l}\text { Formulae are useful during certain steps of the } \\
\text { prescribing process (e.g. drug dose calculations) but } \\
\text { only form one part of a complex process }\end{array}$ \\
\hline & $\begin{array}{l}\text { 2. Experience is useful but gives no } \\
\text { assurance of future success }\end{array}$ & $\begin{array}{l}\text { Even with increasing knowledge, outcomes can be } \\
\text { influenced by situational factors, interpersonal } \\
\text { relationships and wider systems }\end{array}$ \\
\hline & $\begin{array}{l}\text { 3. Expertise may contribute to success } \\
\text { but may not be necessary or sufficient }\end{array}$ & $\begin{array}{l}\text { Both junior staff members and experienced experts } \\
\text { commit errors and contribute towards the occurrence } \\
\text { of prescribing errors }\end{array}$ \\
\hline & $\begin{array}{l}\text { 4. Every problem and its solution are } \\
\text { unique }\end{array}$ & $\begin{array}{l}\text { Experienced professionals can spot familiar patterns, } \\
\text { allowing them to make professional judgements, but } \\
\text { no situation or solution is identical }\end{array}$ \\
\hline & 5. Uncertainty of outcome & $\begin{array}{l}\text { Prescribing is inherently uncertain, given ambiguous } \\
\text { symptoms, variations in patient factors, medication } \\
\text { response and disease progression, drug interactions } \\
\text { and so on, meaning that a 'correct' answer is difficult } \\
\text { to determine, even in hindsight }\end{array}$ \\
\hline
\end{tabular}

\section{Prescribing as a complex activity}

In order to contextualise our reflections on the term feedback, it is necessary to further describe the features of prescribing which make it an inherently complex task (McLellan et al., 2012). The prescribing process involves numerous stages, can involve multiple healthcare professionals, and is situated within complex social and material environments; necessarily problematising any unidimensional understandings of what feedback in this context might entail. This complexity was neatly illustrated by a process model of prescribing (in this case, focusing on antibiotic prescribing in hospitals), developed to uncover the many disturbances or 'hot spots' which might contribute to error, suggesting multiple targets for intervention (Kajamaa et al., 2019). As illustrated by this model and other research by the team, prescribing is a far from 'clear-cut' process and is rooted within the social contexts in which prescribing occurs (Dornan et al., 2009, McLellan et al., 2015). For instance, although junior doctors are frequently those who write up prescriptions, the prescribing decision itself can involve a variety of people. Senior physicians often give initial instructions, pharmacists and other specialists may discuss and advise, nurses administer medications and provide a further error safety-net, and patients may or may not continue medication regimes following discharge from hospital. Prescribing decisions are also not one-off events, but are regularly reviewed in response to changeable factors such as patient condition and location, side effects, test results, and changes of diagnoses (Kajamaa et al., 2019) given the uncertain and provisional nature of professional medical judgement (Cristancho, Lingard and Regehr, 2017).

These prescribing decisions take place within healthcare environments known to be hectic, demanding and time pressured, with clinicians experiencing frequent interruptions (Rivera-Rodriguez and Karsh, 2010). Interruptions can lead to a loss of task-related information in memory, including intended plans of action (Parker and Coiera, 2000), and introduce errors into the prescription writing process itself (Conn et al., 2019). They can also inhibit critical thinking processes and the holistic understanding of clinical situations required to make good decisions (Chisholm $e t$ al., 2001). Other environmental features which may negatively influence prescribing decision-making and writing include: fatigue from long shifts and night working, high workloads and understaffing which cause clinicians to multi-task and feel 'rushed', a lack of immediate advice from others, and difficulties accessing patient information (Dornan et al., 2009; Ross et al., 2013; Westbrook et al., 2018). Relational aspects of prescribing are also key, as 
hierarchies and dominant professional cultures can inhibit support-seeking behaviours and the questioning of doubtful decisions (Bannan et al., 2019; Charani et al., 2019; Kajamaa et al., 2019). Junior doctors have been the particular focus of many prescribing feedback interventions, given difficult transitions into practice and insufficient prior educational experiences of realistic, clinically-situated prescribing decisions (McLellan et al., 2015).

Given this complexity and breadth of the prescribing process, and the multiplicity of factors which can contribute to error, it seems evident that prescribing feedback interventions also need to be complex - to fully explore which factors may contribute to prescribing performance, and to inform plans of action to improve future prescribing. Our understandings of 'feedback' in this context should therefore be equally nuanced, given that they will inform both the feedback interventions devised and solutions to ensure their implementation. Ensuring that such interventions become embedded in routine healthcare practice is a key aim of this research team (see Table 2).

\section{Our reflective journey (Method)}

As part of an externally-funded project exploring how to improve prescribing feedback for early career doctors, we identified a possible barrier as the word feedback itself, with the co-authors each holding subtly different ideas, beliefs and assumptions about feedback, shaped through their multiple research, teaching and prescribing roles. In addition, through the stakeholder workshops convened for the project, we realised that patients, practitioners and policy makers also held long-established beliefs and assumptions about the term feedback, which were sometimes at odds with our own. We found Barry et al.'s paper (1999) 'Using reflexivity to optimize teamwork in qualitative research' a useful guide to thinking and talking about our own assumptions and conceptualisations, through reflection as a team. Reflexivity emphasizes an awareness of the researcher's own presence in the research process and is often seen as an individual activity. However, Barry and colleagues proposed that "reflexivity [be] employed as a team activity, through the sharing of reflexive writing (accounts of personal agendas, hidden assumptions, and theoretical definitions) and group discussions about arising issues". In this team, we felt that through purposely uncovering team members' 'fore-understandings', and drawing upon their diverse knowledge and experience bases, this would provoke discussion, widen perspectives and generate a wider variety of solutions. Our sharing of reflexive writing and group discussions occurred both implicitly, through the bid writing process, teleconferences and email exchanges, and explicitly, through team meetings and the co-writing of this article. We agree that the benefits of these activities to quality include "increasing rigor, and encouraging richer conceptual analysis and interpretation". Throughout the project we have discussed and debated the key theoretical concepts which apply to our research, and some of these reflections are presented in this article.

Table 2: About the project. 


\section{Optimising prescribing}

Previous research by this team has consistently demonstrated that feedback interventions can substantially reduce prescribing errors (Parker et al., 2019), but such interventions have not always been adopted or sustained as part of routine healthcare practice and postgraduate training. Understanding barriers to implementation is key to ensuring that research evidence is translated into action. With support from ESRC Impact Acceleration funding, our research team has brought together diverse academic and external partners who represent medical education, policy-makers, and clinical practice. These partners are currently engaging with a wide community of key stakeholders, including pharmacists, doctors, nurses, patients, educational programme directors and policy makers, as well as organisations such as the Academic Health Science Network, whose purpose it is to strengthen connections between research and healthcare (The AHSN Network, 2020). This project seeks to gain a richer understanding of patient perspectives on prescribing, the financial costs and benefits of interventions, and the barriers and enablers within healthcare systems, to generate novel solutions. This will lead to the production of an 'Optimising prescribing toolkit' shared via our project website, which provides resources for clinical practitioners to spread knowledge of best practice, and policy makers quick access to evidence syntheses to support policy change.

\section{The problem with feedback (Results)}

Although 'common-sense' conceptions of feedback are not homogenous, they frequently encompass a number of implicit assumptions which we feel may constrain what feedback is able to achieve with regard to optimising tasks such as prescribing. These issues and some of our reflections upon them are shown in Table 3. Given these thorny issues concerning the term feedback, we endeavoured as a group to brainstorm and research suitable alternatives, and these are outlined, with a consideration of their strengths and weaknesses, in Table 4.

Table 3: Implicit assumptions about the term 'feedback', reflections and alternative approaches.

\begin{tabular}{|c|c|}
\hline Implicit assumptions & Reflections and alternative approaches \\
\hline $\begin{array}{l}\text { Unidirectionality and fixed 'roles' } \\
\text { The term feedback usually suggests unidirectional } \\
\text { information flows from teacher to student, where } \\
\text { each performs fixed roles in the process (Ridder } \text { et al., } \\
\text { 2008). However, given that human communication } \\
\text { evolved as a dialogic process (Garrod and Pickering, } \\
\text { 2004), this reduction of feedback to 'transmission' } \\
\text { can reduce learner agency (Molloy, 2010) and inhibit } \\
\text { joint exploration, which might otherwise naturally } \\
\text { unfold and take conversations in unpredictable } \\
\text { directions. }\end{array}$ & $\begin{array}{l}\text { Previous work has demonstrated that learners prefer } \\
\text { interactive, dialogic approaches over unidirectional forms } \\
\text { of feedback (Ramani and Krackow, 2012). This team has } \\
\text { also found that collaborative prescribing conversations } \\
\text { with bi-directional flows of information, questions and } \\
\text { feedback, to support joint reflection, can be more effective } \\
\text { - for increasing knowledge and understanding of both } \\
\text { prescribers and feedback facilitators, and to highlight } \\
\text { salient features of prescribing environments which may } \\
\text { contribute to error (Parker } \text { et al., 2019). }\end{array}$ \\
\hline
\end{tabular}




\section{Power differentials \\ Such ideas of feedback-giver and feedback recipient suggests power differentials between those who possess superior knowledge, information and experience, and those who lack it. Employing 'deficit' models of feedback may inhibit learners from asking questions, thinking through ideas out loud, or from requesting tailored feedback, leading to provision of advice which fails to meet their specific needs (Ramani et al., 2019). Imbalances of perceived power can also cause differential sources of knowledge, expertise and information (whether those be healthcare professionals, patients, or a study of processes and systems), to be unrecognised or under- appreciated.}

\section{Duality}

Related to this, feedback is often interpreted as a process which involves two people. Given the number of professionals involved in complex decisions such as prescribing, feedback needs to reflect this multidirectionality.
During our first workshop, which sought to include patient and public voices, it was noted that prescriber and patient attendees held a variety of conceptions about what feedback entailed and who might be qualified to provide it. For instance, some patients appeared happy to view themselves as 'experts' in their own condition and care, and desired greater levels of control through discourse with their physicians; others expressed feeling unqualified as laymen novices to give feedback to highly trained professionals. More democratic approaches to feedback might therefore draw upon a wide variety of information sources to facilitate knowledge exchange. However, to achieve this the effects of shared social understandings regarding who or what serve as viable sources of information need to be addressed.

There have been some attempts to address this concern within medical education through the use of multisource feedback (MSF), also known as $360^{\circ}$ feedback. For this, feedback is gathered from multiple allied healthcare professionals (AHCPs), patients, peers and administrative staff, in addition to clinical and educational supervisors, to assess physician competency and progress. However, research suggests that both provision and acceptance of MSF can be constrained by social barriers such as ward culture, power imbalances, and perceptions of role and expertise, particularly if unidirectional in nature (Yama et al., 2018).

\section{Individual change}

The term may suggest a goal of individual change. However, it is not possible to wholly separate individuals and their actions from surrounding social and organisational systems, and this is especially important when striving to enact change within complex systems such as healthcare (Greig, Entwistle and Beech, 2012).

\section{Associations}

The term feedback may provoke particular associations (such as assessment or personal judgement) in those who anticipate receiving it, based on their past experiences - mediating the ways it is received, processed and understood, and therefore its effectiveness in facilitating positive change. Similarly, providers and facilitators may hold their own preconceptions about the 'script' that feedback encounters should follow. If there are mismatches between these understandings which remain unacknowledged, this can inhibit effective communication (Sender Liberman et al., 2005).
Broadening the focus to encompass systems as-a-whole can inform more holistic understandings of the affordances and barriers presented to prescribing individuals and professional groups (Engestrom, 2000). It may also suggest multiple solutions, at levels which are both individual and systemic.

Even for professionals working with the same feedback scripts in mind, if these encompass the features discussed above (of unidirectionality, expert-novice power relations and individual change), this is likely to limit what can be achieved within a feedback encounter. For example, feedback providers and recipients may adopt sociallyunderstood roles such as 'diagnostician' or 'attentive listener', leading to asymmetric interactions (Delany and Molloy, 2009). 


\section{Emotions \\ Building on the above point regarding associations, our understandings of feedback and the way we think it should be implemented can also have emotional impacts for those giving and receiving feedback. \\ Although the ability of feedback to elicit negative emotions and impair performance in recipients has long been noted (Kluger and DeNisi, 1996), this aspect may not be adequately captured by current definitions. Good feedback requires rapport, empathy, respect and trust (Sender Liberman et al., 2005), features which may be taken for granted but are notable when absent. Attempts to manage difficult emotions provoked by traditional expert-novice feedback relationships may lead to avoidance of delivering 'bad news' (Ende, 1983) or reticence in soliciting feedback (Mann et al., 2011), resulting in learning opportunities being missed.}

\section{Language and dialogue}

Conventional notions of feedback often fail to explicitly recognise the way in feedback

communications are mediated by language and 'talk'. Viewed as teachers instructing students on how to meet required standards, we can see that misunderstandings regarding intention and meaning of feedback can readily occur, due to socially situated differences in interpretation (Torres and Anguiano, 2016).

\section{Notions of 'error'}

In prescribing, feedback may be inherently bound to notions of 'error', implying the possibility of identifying a single individual who is responsible, at a single place and point in time. In reality, errors are difficult to attribute in this way but are situated contextually - arising from a multistep process, involving multiple professionals, and unfolding over time and place. A narrow focus on technically-defined errors may also lead to other aspects of what we might call 'good prescribing' being neglected.

\section{Notions of 'success'}

The idea of giving feedback to correct errors in the prescribing process also rests on assumptions that good prescribing and prescribing expertise are stable, widely-understood concepts. However, the idea that there can be 'correct' answers in prescribing would be misleading; rather one might aim for better outcomes in what are inevitably situations of uncertainty, through the development of professional judgement.
Such dilemmas again emphasise the need for notions of feedback which extend beyond transmission of factual information to acknowledge its social dimension (Nicol and Macfarlane-Dick, 2006). Although the role of both positive and negative emotions in changing practice, at individual and system level, has not yet been sufficiently explored (Carrieri et al., 2020), it has been noted that feelings of psychological safety are required for learners to be productively involved in learning from feedback (Johnson, Keating and Molloy, 2020).
If we move away from notions of feedback-astransmission towards more dialogic approaches, we could suggest that two or more individuals can co-produce shared understandings of 'good practice' and plan together how this might be achieved. Multidirectional dialogue allows prescribers and feedback facilitators to create an 'educational alliance' (Telio, Ajjawi and Regehr, 2015), through which they co-construct understandings of past events such as prescribing errors, and negotiate or identify possible solutions and actions. In this way, feedback doesn't transfer good practice; it remakes practice.

Our conversations with workshop participants, and past research on patient perspectives of medical safety, have highlighted how patients' priorities around medical safety may differ to those of healthcare professionals'. Patient definitions of 'error' may extend beyond technicalorganisational definitions to include such aspects as management of symptoms and pain, and effective communication of information (Collier, Sorensen and Iedema, 2016). Understanding how patients and the public understand 'good prescribing', and therefore the nature of the feedback required to achieve this, is one important strand of our team's research.

Given this uncertainty, there is a benefit to sharing information and gaining multiple perspectives, so as to collaboratively formulate what good prescribing 'looks like' in a given situation, and strategies for moving in that direction. 


\section{Complexity}

Complex professional learning environments such as clinical workplaces exhibit the features of change, uncertainty and unpredictability (McLellan et al., 2015). Feedback, conceptualised as unidirectional transfers of information between knowledgeable experts and novice learners, un-mediated by emotional responses or language, and un-situated in holistic understandings of social and organisational systems, are therefore likely to be insufficient when applied in these settings.

When faced with the task of optimising complex activities, the mechanisms through which this can be achieved, including feedback, must themselves be complex.

Table 4: Alternative terms for 'feedback', and a consideration of their features, strengths and weaknesses.

\begin{tabular}{|c|c|}
\hline Term & Features, strengths and weaknesses \\
\hline $\begin{array}{l}\text { Feed-forward } \\
\text { Related to the concept of feedback, which involves the assessment } \\
\text { and communication of past events (such as causes of error), is the } \\
\text { idea of feeding forward, which is a constructive assessment of how } \\
\text { to improve future performance (Molloy, 2010). For instance, the } \\
\text { feedforward interview (FFI) (Kluger and Dijk, 2010) aims to } \\
\text { engage the reflective capacities of learners to formulate internal } \\
\text { standards and plans of action, rather than relying upon external } \\
\text { sources of expertise, and through a future-oriented focus, elicit } \\
\text { positive emotional responses. Similarly, solution-focused brief } \\
\text { therapy (SFBT), which has analogous features to the FFI, has been } \\
\text { suggested as an additional mode of feedback to be used in clinical } \\
\text { practice (Molloy, 2010). SFBT also takes a forward-facing focus, } \\
\text { with the aim of creating and having expectations of positive } \\
\text { change in the future (Devlin, 2003). Goals and action plans are } \\
\text { developed by the learner with assistance from a more experienced } \\
\text { educator, with solutions constructed on the basis of past successes, } \\
\text { and continual adaption of strategies if they fail to move the learner } \\
\text { towards their goals. }\end{array}$ & $\begin{array}{l}\text { Feed-forward is a more 'positive' term, } \\
\text { focussing as it does on future practice rather } \\
\text { than past mistakes, thus perhaps reducing } \\
\text { negative emotional associations. However, } \\
\text { both of these techniques retain as a 'key } \\
\text { ingredient', a focus on reducing discrepancies } \\
\text { between preferred and actual standards for } \\
\text { individual learners (p. } 1171 \text {, Kluger and Dijk, } \\
2010 \text { ). Therefore, as for traditional feedback, } \\
\text { they may neglect to capture some of the more } \\
\text { systemic or multi-professional aspects of the } \\
\text { complex process of prescribing. }\end{array}$ \\
\hline
\end{tabular}




\section{Briefing and debriefing}

Systems thinking approaches aim to better understand complex, dynamic environments such as healthcare through a holistic focus on organisational dynamics, interrelationships and repeated patterns, rather than static 'snapshots' of single events, individuals or moments in time (Atun, Coker and McKee, 2008). By understanding how the actions and interactions of individuals are shaped, encouraged or constrained by surrounding contexts, it may be possible to identify 'latent' or systemic causes underlying human error. The aim of such approaches is to move beyond a reductionist focus on individual change or blame, which may actually decrease patient safety through discouraging error disclosure, to promote positive 'safety cultures' (Colbert et al., 2011). Arising from aviation procedures, some healthcare organisations conduct 'root cause analyses' (RCA) after adverse events, and failure modes and effects analyses (FMEA) to proactively identify systemic weak points. This may include feedback from patients and information on near-misses (National Patient Safety Agency, 2004). Given that medical culture can be resistant to change, with physicians learning to tolerate or adapt to systemic threats (Waring, 2007), the solutions devised from the findings of RCAs and FMEAs need to be multilevel, with individuals, teams, tasks and organisations all being targeted (Department of Health, 2000), and effective communication of what change is needed and why. This typically occurs via briefing sessions at the start of shifts and debriefing sessions afterwards, to identify actual or potential safety issues, and avenues of improvement (National Patient Safety Agency, 2004).

The term debriefing was used in a somewhat different sense within MITS (Making Insulin Treatment Safer), an intervention which supports prescribers to optimise insulin prescribing, to increase safety and improve patient experiences. MITS employs case-based discussions (CbDs) to provide safe spaces for prescribers to reflect on recent prescribing events with the support of trained debriefers, who may be doctors, pharmacists, nurses or patient advocates (Queen's University Belfast, 2019). Debriefers are present to facilitate this discussion rather than play the role of 'expert' or critic. Together, the debriefer and prescriber identify areas of good practice and those which require change, set goals, plan actions, and devise ways to overcome any barriers identified. This process is based on $\operatorname{smac}^{2}$ (Carrington et al., 2018), a tool designed to raise situational awareness, and aims to empower professionals and patients to support one another through genuine communication, empathy and respect.
The MITS team is now moving towards the term guided reflection (see below), given reservations about the term debriefing. Given its origins in responses to dealing with adverse incidents, it may not be the most apt term to use in relation to our objective of optimising prescribing, as although this includes the aim of preventing clinically defined errors it also encompasses the improvement of prescribing practice more generally. 


\section{Situation awareness}

Situation awareness (SA), another concept derived from aviation and now applied to healthcare, refers to agents' changing levels of awareness and understanding of their environments, including salient 'cues' which might indicate threats to safety or the need for action, and future projections of events (Salmon et al., 2008;

Gardner, Kosemund and Martinez, 2017). Situation awareness was originally conceptualised as a psychological phenomenon, encompassing what individuals perceive, gather information about and understand of their surroundings. However, a more holistic approach is to see SA as distributed across human and technological agents working together in collaborative systems. Here, knowledge is stored not just as mental representations within individual minds, but also through the shared social understandings and routine practices of teams, within electronic devices, documents and artefacts, and communicated via interactions between these agents (Salmon et al., 2008; Fioratou et al., 2010; Stanton et al., 2010).

\section{Guided, facilitated or supported reflections}

These have been described by the team as 'conversations with a purpose', the idea being that prescribers reflect upon their practice with the support of facilitators who can guide, question and provide alternative perspectives based on their particular expertise and experience (whether that be as a patient advocate or senior medical practitioner). The principles on which these reflective episodes rest are that true learning can only occur in spaces which encourage psychological safety, free from judgement, with twoway flows of information so that the 'system' may also learn from the individual experiences of prescribers.

\section{Structured case-based discussions}

As a term, situational awareness might be considered as one component of the process of identifying factors which contribute to error or non-optimal practice in prescribing. However, it may not be appropriate to describe the practice of feedback as a whole, given a scope which may include but goes beyond technical analyses of environments and their features.
The word reflection might equally apply to individuals or groups thinking about a problem. The words guided, facilitated and supported all suggest the presence of persons who may aid this process, without the power differentials implied by the term feedback.
Case-based discussions (CbD) is a phrase currently employed in postgraduate medical education to refer to formal discussions between foundation trainee doctors and their clinical supervisors about specific recent cases, as a tool for professional learning and formative assessment (Bindal, Wall and Goodyear, 2011).

An advantage of this term is that it is already understood to be a reflective discussion which gives the learner an opportunity to talk about their own experiences, and therefore goes beyond unidirectional feedback provision. However, given its current use, CBDs may imply a hierarchical structure involving an expert teacher and novice learner, and have associations with assessment.

\section{Prescribing conversation or dialogue}

The word dialogue suggests multiple loops of feedback.

Prescribing feedback conversations was the term employed in one of this teams' projects, and was distinguished from ordinary conceptions of feedback to denote feedback events which provide a reflective space, involve joint meaning-making, and collective construction of goals and plans of action (Parker et al., 2019).
The word dialogue suggests an interaction between two parties. The word conversation has broader societal meanings and connotations, implying interactions which are democratic (between parties of equal standing), accessible, with a natural flow of information and ideas in (at least) two directions, and a somewhat unpredictable destination. It may therefore have the advantage of disrupting the formal scripts of behaviour we often hold in mind, and the roles which we adopt, when we think about the word feedback. 


\section{Prescribing consultation}

This may pose an alternative to 'prescribing conversation', implying perhaps a more situated and professional event than conversations which occur during everyday life.
This more professional implication might be seen as an advantage or disadvantage, depending on the level of formality desired and the people involved in a prescribing feedback event. For example, if patient representatives are acting as facilitators then 'consultation' might feel exclusive of nonmedically trained professionals.

\section{Reconceptualising feedback}

An alternative approach to this problem would be to retain the term feedback but reconceptualise it, clearly defining the terms of its use when applied within complex systems such as healthcare education and practice. According to Ridder et al. (2008, p.194) a good definition "..should increase conceptual understanding.. provides insight into a concept's characteristics and explains concept specificity, precision and generalisability; reveals tacit assumptions or presumptions; discloses premises, and makes concept features plain. [It] also specifies procedures to identify or to produce the defined concept reliably."

There has been much literature exploring what constitutes effective feedback; one distinction commonly made is between feedback which is constructive and that which is non-constructive. Constructive feedback aims to correct errors and support learning so as to enhance future performance (Zsohar and Smith, 2009) by providing a 'path to improvement' (Fong et al., 2018, p. 43). Various features of feedback have been proposed to ensure it is constructive, including accuracy, specificity and relevance, direct observation of the learner undertaking tasks, and the observer/feedback-giver having personal knowledge of the learner (Branch and Paranjape, 2002; Van Hell et al., 2009; Chang et al., 2011; Dornan, 2012; Omer and Abdularhim, 2017). There is additionally evidence from systematic reviews that ensuring feedback is accompanied by explicitly stated goals and an action plan for achieving these can increase its effectiveness (Ivers et al., 2014). Feedback should be timely, non-judgmental and delivered with kindness, and feedback sources should be perceived by learners as 'credible', encompassing aspects such as expertise, respect and authenticity of intention (Murdoch-Eaton, 2012; Ramani and Krackow, 2012; Hobson and Malderez, 2013; Telio, Ajjawi and Regehr, 2015; Kuvaas, Buch and Dysvik, 2017). Finally, feedback which is initiated by the learner themselves, which works as a two-way process, and occurs within workplaces promoting feedback-friendly cultures, is suggested to be more effective (Deketelaere et al., 2006; Van Hell et al., 2009; Watling et al., 2012; Ramani, 2016). Clearly, many of these features are positive ones, and encompassing such aims into any definition of feedback may help avoidance of feedback which is too vague, overly critical, provided too late, or with little knowledge of specific learners' needs. However, the compilation of tips for good feedback might perhaps be construed as promoting feedback as a simple intervention, which will surely produce good outcomes if the correct 'recipe' is followed.

Re-framing feedback within sociocultural theories of learning, we can see that feedback is a socially-embedded process which requires active engagement by all parties, and therefore cannot be viewed as the 'product' of simple steps (Price, Handley and Millar, 2011). Recent reflections by medical educators have placed the educational relationship centre stage. For example, Cantillon and Sargeant (2008) highlighted the need to establish a 'comfortable working relationship', so as to reduce negative emotional reactions, and Telio and colleagues (2015) have suggested that an 'educational alliance' between trainers and their supervisees should be developed, similar to that of the therapeutic alliance existing between therapists and their patients. This is in recognition of the social negotiation which the giving and receiving of feedback entails. Central to this relationship are learners' beliefs about their educators regarding: a mutual understanding of the purpose of the educational relationship, an agreement about how this purpose might be jointly achieved, and mutual feelings of 'liking, trusting and valuing' the other (Telio, 
Ajjawi and Regehr, 2015). Molloy and colleagues (Molloy, 2010; Boud and Molloy, 2013; Johnson, Keating and Molloy, 2020) have similarly emphasised the importance of positive social relationships to ensuring that feedback encounters are productive. Ideally, educators will be viewed as trusted 'allies', with the building of psychologically safe spaces to reduce potential 'threats' so that all parties might engage in open, multidirectional dialogue. These theorists have chosen to retain the term feedback, whilst challenging and expanding conceptions of what 'feedback' might look like within professional education. In relation to optimising prescribing, we would agree that it is essential to consider the social aspects of feedback encounters if they are to be effective.

Other researchers have distinguished between different types of feedback. Boud and Molloy (2013; Dawson et al., 2018) have characterised feedback approaches as being conventional, agentic or participatory (Feedback Mark 0,1 and 2). Conventional feedback broadly relates to the traditional conceptions of feedback we have been deconstructing here, where feedback is something which educators initiate and provide in a unidirectional way after events have occurred, in the hope this will have positive effects for individual learners. Agentic feedback goes further, by instigating a feedback loop, such that future feedback is tailored to learners' needs based on observations of learner outcomes. Again, the learner is somewhat passive here, being dependent on educators to discern which gaps in their knowledge exist and what steps might be required to close them. Participatory feedback positions learners as active participants in their own learning, able to elicit the feedback they require to meet their current needs. This type of feedback is conceptualised as dialogic and relational, may involve peers or non-human sources in addition to designated 'teachers', and aims to develop learners' own capacities for self-reflection. Given that this this description of agentic feedback relates to higher education rather than prescribing, it may not encompass all of the features we would value within an ideal prescribing feedback event (for instance, we might expand it to encompass consideration of wider systems). However, it is does suggest a further approach which might be taken - to define different levels or categories of feedback and the particular characteristics of each.

\section{Dilemmas of discourse}

In this article, we have considered some of the implicit assumptions which may accompany the term feedback, and the implications of this when using feedback in healthcare education, particularly in relation to improving complex activities such as prescribing. We have also suggested some alternative terms which might be used in its stead, and some alternative re-imaginings of what feedback might look like if this term is used. Given these possible approaches, to try and shift the dominant discourse which surrounds the word feedback, or to adopt or develop new terminology, we now briefly consider the pros and cons of each.

New terminology arguably frees us from historical associations, disrupting routine ways of thinking and acting. An example of this is the move from discussions of validity and reliability within qualitative research towards terms such as trustworthiness, quality and rigour (Shenton, 2004). Not all qualitative researchers make this choice, but those that do argue that 'validity' and 'reliability' imply standards of practice not appropriate when working within interpretivist paradigms (Tobin and Begley, 2004). On the other hand, there may be pragmatic arguments for retaining and redefining specific terminology, to provide continued links with past literature and allow researchers to tap into wider academic conversations. An example of this might be the continued evolution of the term resilience. Often characterised as a capacity which resides within individual learners (which can be measured or taught), 'resilience' has been reconceptualised by some educational researchers to include an appreciation of how social and organisational contexts may facilitate or inhibit learner agency, and therefore their capacity to enact resilience in the workplace (Johnson and Down, 2013). This use of shared lexicons across disciplines may enhance the potential for researchers from diverse theoretical backgrounds to be brought together and engage in conceptual debates, so allowing underlying meanings (and accompanying practices) to be discussed, challenged and transformed.

To solve this dilemma, it is necessary to judge the extent to which current understandings of a term such as feedback 
inhibit real changes in practice, or instead provide a common ground upon which conversations amongst different parties can occur. The answer to this question may also vary depending on the particular context in which a term is being employed. Therefore, a further approach might be to define and use a range of feedback terms, outlining their strengths and weakness in relation to particular purposes. The context of prescribing does, as we have illustrated here, require a complex definition of feedback so that complex feedback solutions may be implemented in practice. We do not attempt to come to a definitive solution here, but instead seek through the open peer review process of this journal, thoughts from the wider medical education community, inviting them to share their observations and experiences of using feedback in practice.

\section{Take Home Messages}

- The term 'feedback' is of ten accompanied by implicit assumptions of unidirectionality, power differentials, and simple notions of error.

- Feedback delivered with the aim of optimising complex healthcare activities such as prescribing will need to take account of this complexity if it is to be effective.

- We invite discussion from the wider medical education community as to whether suitable alternative terminology exists or if 'feedback' might be re-constructed and re-defined for better use within complex clinical educational settings.

\section{Notes On Contributors}

Helen Foster-Collins, $\mathrm{PhD}$, is a Research Associate with the College of Medicine \& Health, University of Exeter, leading a project to understand the barriers and enablers to implementing prescribing interventions. Her previous ESRC-funded PhD explored the workplace support that newly-qualified doctors and teachers receive during their first year. ORCID ID: https://orcid.org/0000-0003-1602-3306

Karen Mattick, PhD, is a Professor of Medical Education with the College of Medicine \& Health, University of Exeter, and principal investigator for this project which aims to understand the barriers and enablers to implementing prescribing interventions. ORCID ID: https://orcid.org/0000-0003-1800-773X

Richard Conn is an Academic Clinical Lecturer and Paediatrics Specialty Trainee at Queen's University Belfast. His research interests include how healthcare professionals' workplace learning and how education can help to address complex patient safety problems. ORCID ID: https://orcid.org/0000-0002-2564-254X

Michael Lloyd is a Pharmacist and Head of Clinical Education Research at St Helens and Knowlsey Teaching Hospitals. His main research interests focus on safe prescribing and how healthcare professionals learn to prescribe and learn from error, and how educational interventions can help prescribers to develop their prescribing skills and expertise. ORCID ID: https://orcid.org/0000-0002-0619-7540

Tim Dornan is a physician, endocrinologist and medical educationalist. He is Professor at the School of Medicine, Dentistry and Biomedical Sciences at the Queen's University Belfast. His main research interest is clinical workplace learning and especially the application of social learning theories and qualitative methodologies to medical education. ORCID ID: https://orcid.org/0000-0001-7830-0183 


\section{Acknowledgements}

Sincere thanks go to our external partners for their contributions to this project: Nicholas Bennett (St. Helens \& Knowsley NHS Trust), Rob Bethune (Royal Devon \& Exeter NHS Foundation Trust), Angela Carrington (Northern Ireland medicines governance team), Florence Findlay-White (Independent health research \& training consultant) and Stuart Monk (The South West Academic Health Science Network). Also, the attendees of our recent workshop on optimising prescribing, for their valuable perspectives as patient and public representatives.

\section{Bibliography/References}

The AHSN Network (2019) Supporting innovation, AHSN Network. Available at:

http://www.ahsnnetwork.com/supporting-innovation (Accessed: 20/04/2020).

Atun, R., Coker, R. and McKee, M. (2008) Health systems and the challenge of communicable diseases experiences from Europe and Latin America. Maidenhead, England: Open University Press.

Bannan, D. F., Aseeri, M. A., AlAzmi, A. and Tully, M. P. (2019) 'Understanding the causes of prescribing errors from a behavioural perspective', Research in Social and Administrative Pharmacy, 15(5), pp. 546-557. https://doi.org/10.1016/j.sapharm.2018.07.007

Barry, C. A., Britten, N., Barber, N., Bradley, C., et al. (1999) 'Using Reflexivity to Optimize Teamwork in Qualitative Research', Qualitative Health Research, 9(1), pp. 26-44. https://doi.org/10.1177/104973299129121677

Beckett, D. and Hager, P. (2002) Life, Work and Learning: Practice in Postmodernity. Routledge International Studies in Philosophy of Education; No. 14. Taylor \& Francis.

Bereiter, C. (2002) Education and mind in the knowledge age. Routledge.

Bindal, T., Wall, D. and Goodyear, H. M. (2011) 'Trainee doctors' views on workplace-based assessments: Are they just a tick box exercise?', Medical Teacher. Taylor \& Francis, 33(11), pp. 919-927.

https://doi.org/10.3109/0142159X.2011.558140

Blix, H. S., Viktil, K. K., Moger, T. A. and Reikvam, A. (2010) 'Drugs with narrow therapeutic index as indicators in the risk management of hospitalised patients', Pharmacy Practice, 8(1), pp. 50-55.

https://doi.org/10.4321/s1886-36552010000100006

Boud, D. and Molloy, E. (2013) Feedback in Higher and Professional Education: Understanding it and Doing it Well. Routledge.

Branch, W. T. J. and Paranjape, A. (2002) 'Feedback and Reflection: Teaching Methods for Clinical Settings', Academic Medicine, 77(12 Part 1), pp. 1185-1188. https://doi.org/10.1097/00001888-200212000-00005

Bull, S., Mattick, K. and Postlethwaite, K. (2013) "Junior doctor decision making: isn't that an oxymoron?" A qualitative analysis of junior doctors' ward-based decision-making', Journal of Vocational Education \& Training, 65(3), pp. 402-421. https://doi.org/10.1080/13636820.2013.834955

Cantillon, P., and Sargeant, J. (2008) 'Giving feedback in clinical settings', BMJ, 337(nov10 2), p. a1961. https://doi.org/10.1136/bmj.a1961

Carrieri, D., Pearson, M., Mattick, K., Papoutsi, C., et al. (2020) 'Interventions to minimise doctors' mental ill-health and its impacts on the workforce and patient care: the Care Under Pressure realist review', Health Services and 
Delivery Research, 8(19), pp. 1-132. https://doi.org/10.3310/hsdr08190

Carrington, A., Dornan, T., Carragher, A. and Millar, D. (2018) 'Promoting safer prescribing: sustaining, scaling and spreading SMAC2'. $Q$ health. Available at:

https://q.health.org.uk/idea/2018/promoting-safer-prescribing-sustaining-scaling-and-spreading-smac2/ (Accessed:

20/04/2020).

Chang, A., Chou, C. L., Teherani, A. and Hauer, K. E. (2011) 'Clinical skills-related learning goals of senior medical students after performance feedback', Medical Education, 45(9), pp. 878-885.

https://doi.org/10.1111/j.1365-2923.2011.04015.x

Charani, E., Ahmad, R., Rawson, T. M., Castro-Sanchèz, E., et al. (2019) 'The differences in antibiotic decisionmaking between acute surgical and acute medical teams: An ethnographic study of culture and team dynamics', Clinical Infectious Diseases, 69(1), pp. 12-20. https://doi.org/10.1093/cid/ciy844

Chisholm, C. D., Dornfeld, A. M., Nelson, D. R. and Cordell, W. H. (2001) 'Work interrupted: A comparison of workplace interruptions in emergency departments and primary care offices', Annals of Emergency Medicine, 38(2), pp. 146-151. https://doi.org/10.1067/mem.2001.115440

Colbert, C. Y., Ogden, P. E., Ownby, A. R. and Bowe, C. (2011) 'Systems-Based Practice in Graduate Medical Education: Systems Thinking as the Missing Foundational Construct', Teaching and Learning in Medicine, 23(2), pp. 179-185. https://doi.org/10.1080/10401334.2011.561758

Collier, A., Sorensen, R. and Iedema, R. (2016) 'Patients' and families' perspectives of patient safety at the end of life: a video-reflexive ethnography study', International Journal for Quality in Health Care, 28(1), pp. 66-73. https://doi.org/10.1093/intqhe/mzv095

Conn, R. L., Kearney, O., Tully, M. P., Shields, M. D., et al. (2019) 'What causes prescribing errors in children? Scoping review', BMJ Open. British Medical Journal Publishing Group, 9(8), p. e028680. https://doi.org/10.1136/bmjopen-2018-028680

Cristancho, S., Lingard, L. and Regehr, G. (2017) 'From problem solving to problem definition: scrutinizing the complex nature of clinical practice', Perspectives on Medical Education, 6(1), pp. 54-57.

https://doi.org/10.1007/s40037-016-0314-0

Dawson, P., Henderson, M., Ryan, T., Mahoney, P., et al. (2018) 'Technology and Feedback Design', in Spector, M. J., Lockee, B. B., and Childress, M. D. (eds) Learning, Design, and Technology. Cham: Springer International Publishing, pp. 1-45. https://doi.org/10.1007/978-3-319-17727-4_124-1

Deketelaere, A., Kelchtermans, G., Struyf, E. and Leyn, P. D. (2006) 'Disentangling clinical learning experiences: an exploratory study on the dynamic tensions in internship', Medical Education, 40(9), pp. 908-915.

https://doi.org/10.1111/j.1365-2929.2006.02551.x

Delany, C. and Molloy, E. (2009) Clinical Education in the Health Professions: An Educator's Guide. Elsevier Health Sciences.

Department of Health (2000) An organisation with a memory. London: The Stationery Office. Available at: http://www.dh.gov.uk/prod_consum_dh/groups/dh_digitalassets/@dh/@en/documents/digitalasset/dh_4065086.pdf (Accessed: 20/04/2020).

Devlin, M. (2003) 'A solution-focused model for improving individual university teaching', International Journal for Academic Development, 8(1-2), pp. 77-89. https://doi.org/10.1080/1360144042000277955 
Dornan, T. (2012) 'Workplace learning', Perspectives on Medical Education, 1(1), pp. 15-23.

https://doi.org/10.1007/s40037-012-0005-4

Dornan, T., Conn, R., Monaghan, H., Kearney, G., et al. (2019) 'Experience Based Learning (ExBL): Clinical teaching for the twenty-first century', Medical Teacher, 41(10), pp. 1098-1105.

https://doi.org/10.1080/0142159X.2019.1630730

Dornan, T., Lewis, P., Miles, J., Taylor, D., et al. (2009) 'An in depth investigation into causes of prescribing errors by foundation trainees in relation to their medical education: EQUIP study', London: General Medical Council, pp.1-215. Available

at: https://www.gmc-uk.org/-/media/documents/FINAL_Report_prevalence_and_causes_of_prescribing_errors.pdf_ 28935150.pdf (Accessed: 20/04/2020).

Ende, J. (1983) 'Feedback in Clinical Medical Education', JAMA, 250(6), pp. 777-781.

https://doi.org/10.1001/jama.1983.03340060055026

Engestrom, Y. (2000) 'Activity theory as a framework for analyzing and redesigning work', Ergonomics, 43(7), pp. 960-974. https://doi.org/10.1080/001401300409143

Fioratou, E., Flin, R., Glavin, R. and Patey, R. (2010) 'Beyond monitoring: distributed situation awareness in anaesthesia', British Journal of Anaesthesia, 105(1), pp. 83-90. https://doi.org/10.1093/bja/aeq137

Fong, C. J., Schallert, D. L., Williams, K. M., Williamson, Z. H., et al. (2018) 'When feedback signals failure but offers hope for improvement: A process model of constructive criticism', Thinking Skills and Creativity, 30, pp. 42-53. https://doi.org/10.1016/j.tsc.2018.02.014

Gardner, A. K., Kosemund, M. and Martinez, J. (2017) 'Examining the Feasibility and Predictive Validity of the SAGAT Tool to Assess Situation Awareness Among Medical Trainees', Simulation in Healthcare, 12(1), pp. 17-21. Available at: https://pubmed.ncbi.nlm.nih.gov/27504889/ (Accessed: 20/04/2020).

Garrod, S. and Pickering, M. J. (2004) 'Why is conversation so easy?', Trends in Cognitive Sciences, 8(1), pp. 8-11. https://doi.org/10.1016/j.tics.2003.10.016

Glouberman, S. and Zimmerman, B. (2004) '1 Complicated and Complex Systems: What Would Successful Reform of Medicare Look Like?', in Forest, P.-G., Marchildon, G., and McIntosh, T. (eds) Changing Health Care in Canada. Toronto: University of Toronto Press. https://doi.org/10.3138/9781442672833-004

Greig, G., Entwistle, V. A. and Beech, N. (2012) 'Addressing complex healthcare problems in diverse settings: Insights from activity theory', Social Science \& Medicine. (Part Special Issue: Organization studies and the analysis of health systems), 74(3), pp. 305-312. https://doi.org/10.1016/j.socscimed.2011.02.006

Hager, P. (2004) 'Lifelong learning in the workplace? Challenges and issues', Journal of Workplace Learning. Emerald Group Publishing Limited, 16(1/2), pp. 22-32. https://doi.org/10.1108/13665620410521486

Hancock, J. and Mattick, K. (2012) 'Increasing students' tolerance of ambiguity: the need for caution', Academic Medicine: Journal of the Association of American Medical Colleges, 87(7), pp. 834; author reply 835.

https://doi.org/10.1097/ACM.0b013e318257d085

Hattie, J. and Timperley, H. (2007) 'The Power of Feedback', Review of Educational Research, 77(1), pp. 81-112. https://doi.org/10.3102/003465430298487

Hobson, A. J. and Malderez, A. (2013) 'Judgementoring and other threats to realizing the potential of school-based mentoring in teacher education', International Journal of Mentoring and Coaching in Education, 2(2), pp. 89-108. 
https://doi.org/10.1108/IJMCE-03-2013-0019

Ivers, N. M., Sales, A., Colquhoun, H., Michie, S., et al. (2014) 'No more 'business as usual' with audit and feedback interventions: towards an agenda for a reinvigorated intervention'. Implementation Science, 9(1), 14.

https://doi.org/10.1186/1748-5908-9-14

Johnson, B., and Down, B. (2013) Critically re-conceptualising early career teacher resilience. Discourse: Studies in the Cultural Politics of Education, 34(5), pp. 703-715. https://doi.org/10.1080/01596306.2013.728365

Johnson, C. E., Keating, J. L. and Molloy, E. K. (2020) 'Psychological safety in feedback: What does it look like and how can educators work with learners to foster it?', Medical Education, 54(6), pp. 559-570.

https://doi.org/10.1111/medu.14154

Kajamaa, A., Mattick, K., Parker, H., Hilli, A., et al. (2019) 'Trainee doctors' experiences of common problems in the antibiotic prescribing process: an activity theory analysis of narrative data from UK hospitals', BMJ Open. British Medical Journal Publishing Group, 9(6), p. e028733. https://doi.org/10.1136/bmjopen-2018-028733

Kluger, A. N. and DeNisi, A. (1996) 'The effects of feedback interventions on performance: A historical review, a meta-analysis, and a preliminary feedback intervention theory.', Psychological Bulletin, 119(2), pp. 254-284.

https://doi.org/10.1037/0033-2909.119.2.254

Kluger, A. N. and Dijk, D. V. (2010) 'Feedback, the various tasks of the doctor, and the feedforward alternative', Medical Education, 44(12), pp. 1166-1174. https://doi.org/10.1111/j.1365-2923.2010.03849.x

Kuvaas, B., Buch, R. and Dysvik, A. (2017) 'Constructive Supervisor Feedback is not Sufficient: Immediacy and Frequency is Essential', Human Resource Management, 56(3), pp. 519-531. https://doi.org/10.1002/hrm.21785

Mann, K., van der Vleuten, C., Eva, K., Armson, H., et al. (2011) 'Tensions in Informed Self-Assessment: How the Desire for Feedback and Reticence to Collect and Use It Can Conflict', Academic Medicine, 86(9), pp. 1120-1127. https://doi.org/10.1097/ACM.0b013e318226abdd

Maxwell, S. and Wilkinson, K. (2007) 'Writing safe and effective prescriptions in a hospital kardex', J R Coll Physicians Edinb, 37, pp. 348-51. Available at: https://www.rcpe.ac.uk/sites/default/files/maxwell.pdf (Accessed: 20/04/2020).

McLellan L, Tully MP, Dornan T. (2012) How could undergraduate education prepare new graduates to be safer prescribers? Br J Clin Pharmacol, 74, 605-13. https://doi.org/10.1111/j.1365-2125.2012.04271.x

McLellan, L., Yardley, S., Norris, B., de Bruin, A., et al. (2015) 'Preparing to prescribe: How do clerkship students learn in the midst of complexity?', Advances in Health Sciences Education, 20(5), pp. 1339-1354.

https://doi.org/10.1007/s10459-015-9606-0

Molloy, E. K. (2010) 'The feedforward mechanism: a way forward in clinical learning?', Medical Education, 44(12), pp. 1157-1159. https://doi.org/10.1111/j.1365-2923.2010.03868.x

Murdoch-Eaton, D. (2012) 'Feedback: the complexity of self-perception and the transition from "transmit" to "received and understood"', Medical Education, 46(6), pp. 538-540.

https://doi.org/10.1111/j.1365-2923.2012.04278.x

Nicol, D. J., and Macfarlane-Dick, D. (2006) Formative assessment and self-regulated learning: A model and seven principles of good feedback practice. Studies in Higher Education, 31(2), pp. 199-218.

https://doi.org/10.1080/03075070600572090

National Patient Safety Agency, (2004) Seven steps to patient safety: the full reference guide. National Patient Safety 
Agency. Available

at: https://www.publichealth.hscni.net/sites/default/files/directorates/files/Seven\%20steps\%20to\%20safety.pdf (Acce ssed: 20/04/2020).

Omer, A. A. and Abdularhim, M. (2017) 'The criteria of constructive feedback: The feedback that counts', Journal of Health Specialties, 5(1), p. 45.

Parker, H., Farrell, O., Bethune, R., Hodgetts, A., et al. (2019) 'Pharmacist-led, video-stimulated feedback to reduce prescribing errors in doctors-in-training: A mixed methods evaluation', British Journal of Clinical Pharmacology, 85(10), pp. 2405-2413. https://doi.org/10.1111/bcp.14065

Parker, J. and Coiera, E. (2000) 'Improving Clinical Communication: A View from Psychology', Journal of the American Medical Informatics Association. Oxford Academic, 7(5), pp. 453-461.

https://doi.org/10.1136/jamia.2000.0070453

Price, M., Handley, K., and Millar, J. (2011) 'Feedback: Focusing attention on engagement', Studies in Higher Education, 36(8), pp. 879-896. https://doi.org/10.1080/03075079.2010.483513

Queen's University Belfast (2019) 'MITS Structured Case Based Discussion Operating Procedures Version 1.0 - July 2019'. Queen's University Belfast.

Ramani, S. and Krackov, S. K. (2012) 'Twelve tips for giving feedback effectively in the clinical environment', Medical Teacher, 34(10), pp. 787-791. https://doi.org/10.3109/0142159X.2012.684916

Ramani, S. (2016) 'Reflections on feedback: Closing the loop', Med Teach, 38(2), pp. 206-207. https://doi.org/10.3109/0142159x.2015.1044950

Ramani, S., Könings, K. D., Ginsburg, S. and van der Vleuten, C. P. M. (2019) 'Twelve tips to promote a feedback culture with a growth mind-set: Swinging the feedback pendulum from recipes to relationships', Medical Teacher, 41(6), pp. 625-631. https://doi.org/10.1080/0142159X.2018.1432850

Ridder, J. M. M. V. D., Stokking, K. M., McGaghie, W. C. and Cate, O. T. J. T. (2008) 'What is feedback in clinical education?', Medical Education, 42(2), pp. 189-197. https://doi.org/10.1111/j.1365-2923.2007.02973.x

Rivera-Rodriguez, A. J. and Karsh, B. T., (2010) 'Interruptions and distractions in healthcare: review and reappraisal', BMJ Quality \& Safety, 19(4), pp.304-312. https://doi.org/10.1136/qshc.2009.033282

Rogers, P. J. (2008) 'Using programme theory to evaluate complicated and complex aspects of interventions', Evaluation. SAGE Publications Ltd, 14(1), pp. 29-48. https://doi.org/10.1177/1356389007084674

Ross, S., Ryan, C., Duncan, E. M., Francis, J. J., et al. (2013) 'Perceived causes of prescribing errors by junior doctors in hospital inpatients: a study from the PROTECT programme', BMJ Quality \& Safety, 22(2), pp. 97-102. https://doi.org/10.1136/bmjqs-2012-001175

Sadler, D. R. (1989) 'Formative assessment and the design of instructional systems', Instructional Science, 18(2), pp. 119-144. https://doi.org/10.1007/BF00117714

Salmon, P. M., Stanton, N. A., Walker, G. H., Baber, C., et al. (2008) 'What really is going on? Review of situation awareness models for individuals and teams', Theoretical Issues in Ergonomics Science, 9(4), pp. 297-323.

https://doi.org/10.1080/14639220701561775

Sender Liberman, A., Liberman, M., Steinert, Y., McLeod, P., et al. (2005) 'Surgery residents and attending surgeons have different perceptions of feedback', Medical Teacher, 27(5), pp. 470-472.

https://doi.org/10.1080/0142590500129183 
Shenton, A. K. (2004) 'Strategies for ensuring trustworthiness in qualitative research projects', Education for Information, 22(2), pp. 63-75. https://doi.org/10.3233/EFI-2004-22201

Stanton, N. A., Salmon, P. M., Walker, G. H. and Jenkins, D. P. (2010) 'Is situation awareness all in the mind?', Theoretical Issues in Ergonomics Science, 11(1-2), pp. 29-40. https://doi.org/10.1080/14639220903009938

Telio, S., Ajjawi, R. and Regehr, G. (2015) 'The "Educational Alliance" as a Framework for Reconceptualizing Feedback in Medical Education', Academic Medicine, 90(5), pp. 609-614.

https://doi.org/10.1097/ACM.0000000000000560

Tobin, G. A. and Begley, C. M. (2004) 'Methodological rigour within a qualitative framework', Journal of Advanced Nursing, 48(4), pp. 388-396. https://doi.org/10.1111/j.1365-2648.2004.03207.x

Torres, J. and Anguiano, Carlos J (2016) 'Interpreting Feedback: A Discourse Analysis of Teacher Feedback and Student Identity', Practitioner Research in Higher Education, 10(2), pp. 2-11. Available at: https://ojs.cumbria.ac.uk/index.php/prhe/article/view/331 (Accessed: 20/04/2020).

Van Hell, E. A., Kuks, J. B., Raat, A. N., Van Lohuizen, M. T., et al. (2009) 'Instructiveness of feedback during clerkships: Influence of supervisor, observation and student initiative', Medical Teacher, 31(1), pp. 45-50. https://doi.org/10.1080/01421590802144294

Waring, J. J. (2007) 'Doctors' thinking about "the system" as a threat to patient safety', Health, 11, pp. 29-46. https://doi.org/10.1177/1363459307070801

Watling, C., Driessen, E., van der Vleuten, C. P. and Lingard, L. (2012) 'Learning from clinical work: the roles of learning cues and credibility judgements', Medical Education, 46(2), pp. 192-200.

https://doi.org/10.1111/j.1365-2923.2011.04126.x

Westbrook, J. I., Raban, M. Z., Walter, S. R. and Douglas, H. (2018) 'Task errors by emergency physicians are associated with interruptions, multitasking, fatigue and working memory capacity: a prospective, direct observation study', BMJ Quality \& Safety, 27(8), pp. 655-663. https://doi.org/10.1136/bmjqs-2017-007333

Wheeler, D. W., Remoundos, D. D., Whittlestone, K. D. and Palmer, M. I., et al. (2004) 'Doctors' Confusion over Ratios and Percentages in Drug Solutions: The Case for Standard Labelling', Journal of the Royal Society of Medicine. SAGE Publications, 97(8), pp. 380-383. https://doi.org/10.1177/014107680409700805

Yama, B. A., Hodgins, M., Boydell, K. and Schwartz, S. B. (2018) 'A qualitative exploration: questioning multisource feedback in residency education', BMC Medical Education, 18(1), p. 170.

https://doi.org/10.1186/s12909-018-1270-7

Zsohar, H. and Smith, J. A. (2009) 'The power of and and but in constructive feedback on clinical performance', Nurse Educator, 34(6), pp. 241-243. https://doi.org/10.1097/NNE.0b013e3181c0dac7

\section{Appendices}

None.

\section{Declarations}

The author has declared that there are no conflicts of interest. 
This has been published under Creative Commons "CC BY 4.0" (https://creativecommons.org/licenses/by-sa/4.0/)

\section{Ethics Statement}

Ethics approval was not required as this was not a piece of primary research.

\section{External Funding}

This research project has been funded by an ESRC Impact Acceleration Account (IAA). Project title. Optimising prescribing feedback conversations: enabling and empowering prescribers to enhance prescribing development and patient care. (No grant no. available).

MedEdPublish: rapid, post-publication, peer-reviewed articles on healthcare professions' education. For more information please visit www.mededpublish.org or contact mededpublish@dundee.ac.uk. 